Max-Planck-Institut für demografische Forschung

Max Planck Institute for Demographic Research

Konrad-Zuse-Strasse 1 - D-18057 Rostock = Germany = Tel +49 (0) 3812081 - 0 - Fax +49 (0) 3812081 - 202 - www.demogr.mpg.de

MPIDR Working Paper WP 2017-008 I March 2017

Does the Age Difference

Between Partners Influence

the Career Achievements of Women?

Anna Oksuzyan I oksuzyan@demogr.mpg.de

Angela Carollo I carollo@demogr.mpg.de

Sven Drefahl

Carlo Giovanni Camarda

Kaare Christensen

Alyson van Raalte

(C) Copyright is held by the authors.

Working papers of the Max Planck Institute for Demographic Research receive only limited review. Views or opinions expressed in working papers are attributable to the authors and do not necessarily reflect those of the Institute. 


\section{Does the Age Difference Between Partners Influence the Career Achievements of Women?}

Anna Oksuzyan ${ }^{1,2}$, Angela Carollo ${ }^{1,3}$, Sven Drefahl ${ }^{4}$, Carlo Giovanni Camarda ${ }^{5}$, Kaare Christensen ${ }^{2,3,6,7}$, Alyson van Raalte ${ }^{1}$

1 - Max Planck Institute for Demographic Research, Rostock, Germany

2 - Epidemiology, Biostatistics, and Biodemography Unit, Institute of Public Health, University of Southern Denmark, Odense, Denmark

3 - Max Planck Odense Center on the Biodemography of Aging, Institute of Public Health, Odense, Denmark

4 - Stockholm University, Stockholm, Sweden

5 - Institut National d'Études Démographiques, Paris, France

6 - The Danish Twin Registry, Institute of Public Health, University of Southern Denmark, Odense, Denmark

7 - Department of Clinical Genetics and Department of Clinical Biochemistry and Pharmacology, Odense University Hospital, Odense, Denmark

Corresponding author:

Angela Carollo

Max Planck Institute for Demographic Research

Konrad-Zuse-Straße 1

18057 Rostock, Germany

Phone: +49 (0)381 2081-205

Email: carollo@demogr.mpg.de

\section{Acknowledgments}

The study was supported by the US National Institute of Health (NIH) grants P01AG031719, R01AG026786, and 2P01AG031719, and the VELUX Foundation (http://veluxfonden.dk).

$A O, A v R, S D$, and $C G G$ conceived the research question and designed the study; $K C$ and $A O$ obtained the data; $A C$ and CGG conceived the main analytical strategy, AC performed all the analysis. AC, AO, AvR, and SD drafted the manuscript. All of the authors interpreted the results, reviewed the drafts, provided critical feedback, and approved the final manuscript. 


\begin{abstract}
Women earn less than men at most career stages, and they also tend to partner with older men. This study investigates whether being the younger partner in a marriage reduces a woman's incentive to pursue an independent career. We hypothesize that the income gender gap might be partially explained by the age differences between spouses. Using both a within-twin $(n=4716)$ and pooled-twin $(n=$ 13354) design to more readily account for differences in early household environments, we investigated for Denmark whether the age gap between a female twin and her partner has any influence on her income. The hypothesis could not be confirmed, as the age gap between partners did not appear to be associated with women's earnings. The finding that women's wages were generally unaffected by partnering with an older man could be a result of heterogeneous groups of women entering men-older partnerships. Future research should explore this question further by using the number of promotions to assess the career success of women, and should extend this work to countries with different social welfare systems and less egalitarian gender norms.
\end{abstract}

Keywords: age homogamy, gender wage gap, twin design, Denmark, register data, quantile regression 


\section{Introduction}

The gender gap in income is large and persists throughout the life course. In the 28 countries of the European Union, the average gender wage gap ${ }^{1}$ in 2014 was about $16.7 \%$, and ranged from $4.5 \%$ in Romania to $28.1 \%$ in Estonia (Eurostat 1994-2014). Men out-earn women starting with their entry into the labor market. Gender differences in pay remain large throughout the early career stages (Kunze 2005), and even increase with age (Eurostat 2008).

A substantial body of research has investigated the reasons for the gender differences in labor market outcomes in general, and in the gender wage gap in particular. In addition to examining gender segregation into educational fields and labor market segments, the existing theoretical work has primarily focused on gender differences in the allocation of household work and family responsibilities. This body of work includes theoretical accounts of relative resource bargaining (Blood and Wolfe 1960), household specialization (Becker 1981), as well as the "doing gender" hypothesis (West and Zimmerman 1987).

In this study, we explore the role of age differences between spouses in explaining the gender wage gap. The marital age gap is of particular theoretical interest because it is a factor that is shared and determined at the couple level; but that is also associated with specific properties for each of the partners. Decisions that appear to be optimal at the household level might not be optimal for each individual partner. As a consequence, the age difference may determine a portion of the resourcebargaining power within the relationship, as well as the pathways toward specific forms of household specialization. For example, since income tends to rise with age, the older partner is likely to contribute more than the younger partner to the household's economic resources. The larger the age difference is, the greater the age-related income gap is likely to be. Thus, if the younger partner contributes less to the household's economic security, s/he will have fewer incentives to pursue her/his own career ambitions. Moreover, at least in the short term, the best strategy a couple can use to maximize their household income is likely to be optimizing the income and the career prospects of the older, higher earner.

Because women have a tendency to marry older men, a woman is much more likely than a man to be the lower earner in a couple. We hypothesize that, on average, a woman with an older partner is more willing to compromise her own career trajectory than a woman with a partner who is the same age or younger. Additionally, given the secular uptake in the sharing of domestic and child care activities, it appears that in some cases a woman who partners with an older man is expected to take on a larger share of the household responsibilities because her husband has more traditional gendered values. These expectations could lead her to reduce her working hours, which has a direct dampening effect on her wages. Alternatively, a woman who partners with an older man may be indirectly signaling a lower commitment to paid work, and a willingness to take on a greater share of the domestic duties. In

\footnotetext{
${ }^{1}$ Measured as the difference between the average gross hourly earnings of male and of female paid employees as a percentage of average gross hourly earnings of male paid employees.
} 
Sweden, each additional month of parental leave uptake by the father has been found to be associated with a $6.7 \%$ increase in the mother's wages (Johansson 2010). A woman of a given age in a partnership with a man of the same age or younger might be expected to realize more income gains than a woman in a partnership with an older man, based on the assumption that a younger man is more likely than an older man to take parental leave and contribute to the household responsibilities (Tervola, Duvander et al. 2016).

We tested these hypotheses using data on married Danish female twins, and on the age gap between these women and their male husbands. The analysis was carried out using both a within-twin pair study design to control for unobserved family characteristics, and a pooled sample design to increase the sample size.

\section{Background}

\section{Gender Gap in Pay}

A number of explanations for why men earn more than women have been proposed, including gender differences in qualifications and occupational structures. It has also been argued that women face more difficulties than men in climbing the occupational ladder because of gender role expectations and their life course trajectories.

In the mid- to late-twentieth century, it was posited that a substantial share of the male-female wage differential could be explained by differences in occupational qualifications upon entry into the labor market, and that these differences were an important determinant of future wage prospects (Blau and Kahn 2000; Kunze 2005). However, although the educational attainment of women has increased considerably in recent years, with women having even higher educational qualifications than men in many countries, the gender wage gap persists in all countries (Eurostat 1994-2014).

Comparative international studies have suggested that the gender wage gap is influenced by wage structures; i.e., "prices determined for labor market skills and the rewards to employment in particular sectors" (Blau and Kahn 2000). Rosholm and Smith (1996) showed that differences in human capital (education and experience) between the sexes explained little of the stagnating gender wage equalization in Denmark in the 1980s. They instead attributed this trend mainly to a combination of higher wage growth in the private sector than in the public sector, which employed higher proportions of women; and to increased wage dispersion in this period, especially in the private sector. More recent studies conducted across the EU countries and in the U.S. have found wider gender wage differentials in the private than in the public sectors, especially at the top of the wage distribution (the "glass ceiling" effect), and to a lesser extent at the bottom top of the wage distribution ("sticky floor" effect). However, the magnitudes of these differentials appear to vary substantially across countries (Arulampalam, Booth et al. 2007; Miller 2009; Christofides, Polycarpou et al. 2013). The wage structure has been shown to be a particularly important factor in the gender pay gap. Blau and Kahn (2000) argued that the wage differences between men and women in the U.S. would be more similar to those in some European 
countries if these countries had more equal wage structures. This observation suggests that centralized systems of pay determination tend to reduce overall levels of wage inequality, including the gender pay gap.

Some empirical analyses have investigated how non-cognitive traits affect gender wage differentials (Fortin 2008). Studies conducted in Sweden have shown that the glass ceiling effect is especially pronounced in the public sector, in which individual wage negotiations are common; possibly because women are less likely to negotiate their compensation and respond differently to negotiation outcomes (Säve-Söderbergh 2007; Wahlberg 2010). Similarly, a study that examined the gender wage gap in the Netherlands from 1996 to 2006 found that despite the favorable trends in female educational attainment and work experience, and the changes in the observable prices of education among women, men continued to earn considerably more than women (Fransen, Plantenga et al. 2012). The authors theorized that women may have work-related preferences other than compensation that cause them to have lower wages than men.

Studies have also found that women suffer wage penalties for motherhood in the form of reduced work effort, lost human capital, and reduced work experience (Budig and Hodges 2010; Gough and Noonan 2013). Cross-country comparisons have suggested that family-friendly policies (e.g., a long maternity leave with full or partial benefits, heavily subsidized child care facilities, paid leave to care for sick children) and family-friendly employment practices (e.g., reduced employment) tend to increase female labor force participation rates, but can have negative effects on women's wages by encouraging horizontal (more women in stereotypically female jobs) and vertical (fewer women in managerial positions) occupational segregation, and may foster employer discrimination (Mandel and Semyonov 2005; Mandel and Semyonov 2006). However, there is some evidence that the wage penalty for motherhood is largest at younger ages, and diminishes with age among women with three or fewer children (Kahn, García-Manglano et al. 2014). It has also been shown that women may be penalized for taking a longer than average maternity leave (Evertsson and Duvander 2010).

In Denmark, the adoption of the principle of equality of pay for men and women in 1973 and its enforcement by the European Union starting in 1976 led to a reduction in the gender pay gap in the 1970s (Rosholm and Smith 1996). Although this trend plateaued in the 1980s, at least in the private sector; Denmark continued to have a smaller gender pay gap than the Netherlands, Germany, Ireland, the UK, and the U.S. until the early 1990s. The Swedish and the Finnish experiences were similar to those of Denmark from the early 1980s to the early 1990s, while the gender wage gap was steadily declining in Norway (Rosholm and Smith 1996). In 2014, the average Danish woman earned 16.0\% less than the average Danish man, a figure that is only slightly below the EU-28 average (16.6\%) (Eurostat 1994-2014). When other domains of gender equality are considered, Denmark is found to be among the leading EU countries. In the Gender Equality Index, which measures gender gaps adjusted for level of achievements, Denmark is ranked third after Sweden and Finland (INDEX 2015). In the United Nation's Gender Inequality Index, Denmark is ranked fourth out of the 155 countries included, in part because it has very low levels of inequality in domains such as reproductive health and empowerment (Jahan, Jespersen et al. 2015). 
Reasons for Age Gaps in Marriage

Both currently and historically, the male partner is older than the female partner in the majority of marital unions (Presser 1975; Buss 1989; Gustafson and Fransson 2015). Although it has been shown that the mean age at marriage increased in many developed and developing countries over the $20^{\text {th }}$ century (Billari 2005), trends in spousal age differences have received less attention. The existing studies that have looked at trends in spousal age differences have indicated that there was a shift toward more age-similar marriages in the 20th century in the U.S. (Atkinson and Glass 1985), in Spain (Esteve, Cortina et al. 2009), and in some selected OECD and non-OECD countries (Diez Minguela 2010); but that the opposite pattern occurred in China (Mu and Xie 2014), while the age gap remained stable in Germany (Klein 1996). The spousal age gap narrowed until about 1970 in the Netherlands, but the proportion of marriages in which the age difference was relatively large increased thereafter (Poppel, Liefbroer et al. 2001). Hancock, Stuchbury et al. (2003) showed that although the median spousal age gap remained almost unchanged from 1963 to 1998 in England and Wales, the changes in the age gap pattern that occurred over this period were masked by a substantial increase in the proportion of women-older marriages and a smaller increase in the proportion of men-older marriages. In Denmark, the age gap has remained relatively stable throughout the twentieth century (Drefahl 2010a). From 1955 to 2015, the mean age at first marriage increased from 23.4 to 32.0 among women and from 26.6 to 34.5 among men, which resulted in a narrowing of the marital age gap from 3.2 to 2.5 years (Statistics Denmark 2016).

The most widely cited explanations for the predominance of men-older marriages are embedded in reproductive and economic considerations regarding partnership formation (Buss 1989; Bergstrom and Bagnoli 1993). A man's economic status is an important determinant of his attractiveness as a marriage partner. As socioeconomic status and economic stability tends to increase with age, it is possible that women believe that older men are more stable partners. Conversely, the relative desirability of women as marriage partners is partially determined by their reproductive capacity, which declines with age. Thus, in forming stable partnerships, men tend to prefer younger women, while younger women tend to prefer older male partners who already have visible economic accomplishments.

It has also been suggested that gender equality, the status of women, and gender-related social norms are important determinants of cross-national variation in age differences at marriage. Comparative studies have shown that the age gap is larger in developing countries with more traditional gender roles than in countries with higher levels of gender equality (Casterline, Williams et al. 1986). Social norms may also contribute to the spousal age gap distribution (Presser 1975). Generally, it is more socially acceptable for a woman to marry an older man than a younger man, and large age discrepancies in menolder and, especially, in women-older partnerships are viewed negatively (Banks and Arnold 2001; Lehmiller and Agnew 2006; Lehmiller and Agnew 2008).

Previous empirical research has indicated that having a migration background, having low levels of education and income, and being non-employed are associated with larger spousal age differences (Atkinson and Glass 1985; Vera, Berardo et al. 1985; Berardo, Appel et al. 1993). Recent register-based 
studies have demonstrated that native-born Swedes were more likely to enter into age-similar marriages, while immigrants from low- and middle-income countries were more likely to have large spousal age differences. Among immigrants from high-income countries, male immigrants showed higher propensities to enter age-dissimilar marriages than the native-male population, whereas female immigrants generally had the same propensities as Swedish women to enter such marriages (Niedomysl, Östh et al. 2010; Gustafson and Fransson 2015).

In this work, we aim to disentangle the possible association between women's career achievements and the marital age gap. In the literature, a distinction has generally been made between extrinsic and intrinsic career success: i.e., extrinsic career success is measured in terms of salary and promotions using outcomes that are objectively observable, whereas intrinsic success refers to an individual's subjective evaluation of his or her own goals and career expectations (Seibert 2001).

We operationalized extrinsic career success using income as an objective marker of career success. Drawing upon data on Danish female twins, we tested our hypothesis using both a within-twin pair study design and a pooled sample design. Our results for both analyses indicated that there was no strong association between the marital age gap and women's income.

\section{Data and methods}

\section{Data}

The Danish Twin Registry is the oldest national twin register in the world, and represents a unique source of data for studies of genetic, familial, and environmental factors on life events, health conditions, and diseases. It contains information on more than 86,000 twin pairs born in Denmark since 1870 (Skytthe, Ohm Kyvik et al. 2011)

Under the Civil Registration System (CRS), which has existed in Denmark since 1968, each resident receives a 10-digit unique personal identifier, the Central Personal Register (CPR) number. The CPR number is used to link information across the diverse computerized registers that cover the total Danish population. The present study utilizes the Central Person Register (CPR) (demographics, residence, migration, and civil status since 1968), the Danish Twins Register (demographics, residency, zygosity since 1954), the Integrated Database for Labor Market research (IDA) (income, employment, and education since 1980) and the Population Education Register (PER) (highest education level since 1981) (Baadsgaard and Quitzau 2011; Pedersen 2011; Petersson, Baadsgaard et al. 2011; Skytthe, Christiansen et al. 2012).

In this study, we employ a twin design, which has been used in economics, sociology, and behavioral genetics to examine the relative roles of genetic and social endowments on demographic and socioeconomic outcomes, as well as to estimate the effects of various variables net of such endowments. In addition to having similar genetic characteristics, twins who are raised together experience similar social and economic conditions during childhood and adolescence. Thus, studying 
twins provides us with a unique opportunity to gain a better understanding of how genetic and social endowments affect behaviors and choices in later stages of life (Kohler, Behrman et al. 2011).

The study is based on all female twin pairs born between 1945 and 1990 who were alive and resident in Denmark in 2010. We decided to restrict the sample to women born after 1945 because the structural changes in women's career and family situations started to change in Denmark around the early 1960s (Grunow 2004; Larsen 2015). Prior to that time, it was uncommon for a married woman to engage in paid work. But the rising demand for unskilled labor and service sector employment, combined with women's increased participation in higher education, fundamentally changed the career prospects of these later-born cohorts. Same-sex couples were excluded from the analysis because our main focus is on gender relations.

We decided to restrict our analysis to twins rather than including all sibling pairs in order to better control for unobserved differences in genetic and early environmental conditions, which might be related to selection into partnerships with different age gaps. Moreover, the data on children, which are important to control for when assessing factors that might reduce women's income, were available for the twin population, but not for sibling pairs.

Variables

We identified taxable gross income before deductions as the outcome of interest, converting the data from Danish krone ${ }^{2}$ into U.S. dollars. This indicator includes income from the following sources: wage income, retirement income, transfers from public monies, capital income, and income from abroad. We extracted the variable registered in the year 2010. The demographic information was obtained by the linkage of several registers.

The control variables included in the analysis were marital age difference and age at marriage, as well as age, highest education attained, employment status, retirement status, number of children, and income of partner in 2010. The highest education attained was measured according to the International Standard Classification of Education (ISCED), which in Denmark has seven categories ${ }^{3}$ : ISCED 0, ISCED 1, ISCED 2, ISCED 3, ISCED 5, ISCED 6, and ISCED $7^{4}$ (Eurydice 2014; Eurydice 2016). The employment status is identified as employed, unemployed, and out of the labor force ${ }^{5}$. Retirement status is divided into four categories: not retired, retired, retired early, and early retirement beneficiary; the differences between the last three categories can be determined by looking at the age at retirement and the type of pension plan chosen by the individual. The number of children is included as a factor with four levels: zero, one, two, three or more children. The income of the partner is measured as gross income in 2010,

\footnotetext{
${ }^{2}$ On April 15, 2016, a Danish krona, 1DKK, amounted to about 0.15 U.S. dollars.

${ }^{3}$ We have grouped together the categories ISCED $1 / 2$ and ISCED 5/6 due to sample size. The category ISCED 0 was not observed among women in our study.

${ }^{4}$ ISCED 0 = early childhood education; ISCED 1 = primary education 8-10 grade; ISCED 2 = lower secondary education; ISCED 3 = upper secondary school and training for skilled workers; ISCED 5 = short-cycle tertiary education; ISCED 6 = bachelors' or equivalent level; ISCED 7 = master's or equivalent level and doctoral education. ${ }^{5}$ According to Statistics Denmark, the category out of the labor force includes early retirement, pensioners, students, and other people outside of the labor force.
} 
and is categorized according to the distribution in the population into four categories: low, medium-low, medium-high, and high. Finally, the birth cohort variable distinguishes between women born from 1945 to 1964 (older cohorts) and women born from 1965 to 1990 (younger cohorts). We restricted the analysis to observations with no missing values in the variables. This restriction led us to remove about 1,600 individuals, leaving us with 13,354 individuals.

\section{Statistical Analysis}

We first performed a within-pair analysis in which individuals were included only if both the individual and her twin were alive and married in 2010. Hereafter, we refer to these cases as complete twin pairs. We later perfomed a pooled analysis to increase the size of the population. This analysis also included incomplete twin pairs, such as cases in which one twin was unmarried or deceased. The within-pair results are presented, followed by the pooled analysis on the extended population.

Classical generalized least squares regression models, which explain changes in average income, do not allow for the analysis to be focused on different parts of the distribution. Instead, we used the more flexible quantile regression (Kroenker 2005). Quantile regression allows us to quantify any differences in effects that the age gap between partners and the other covariates might have on different parts of the income distribution, which might be especially important given the asymmetric distribution of income. It also provides us with ways to investigate the potential effects of covariates on the shape of the distribution of the response (Kroenker 2005).

The quantile linear model estimated here has the following form:

$$
y=\mu^{(\tau)}+\varepsilon^{(\tau)}
$$

where $\mu_{i}{ }^{(\tau)}=x_{i}{ }^{T} \beta^{(\tau)}, i=1, \ldots, M$ and $\tau=\{0.10,0.25,0.50,0.75,0.90\}$ are the quantiles selected for the analysis. Here, $\mu_{i}$ is the mean value of gross income in each of the five quantiles estimated, and the errors are independent and identically distributed from a probability density function with positive density on its support. We assume that there is a linear relationship between gross income and the covariates, and that this relationship is different in every quantile considered.

The dependent variable was gross income in 2010, and the control variables were spousal age gap, age, age at marriage, highest education attained, employment status, number of children, and gross income of the partner. Since labor force participation and labor market returns to education might have been expected to change the relationship between income and the covariates, we split the 46 different birth cohorts into an "older cohort" subpopulation born in 1945-1964, and a "younger cohort" subpopulation born in 1965-1990. We then ran the model for each of these cohort groupings based on five income quantiles; that is: $\tau=\{0.10,0.25,0.50,0.75,0.90\}$.

All of the analyses were performed using the R-package quantreg (R Core Team 2014; Koenker, Portnoy et al. 2016). 


\section{Results}

Descriptive Results

To provide us with an initial picture of the relationships among the variables included in the analysis, we considered nine categories of age difference, following the study by (Mansour and McKinnish 2013). Among the complete twin pairs, $30 \%$ of the female twins had a partner who was $2-5$ years older, $23 \%$ had a partner who was one year younger or older, $13 \%$ had a partner who was $1-2$ years older, and $12 \%$ had a partner who was 5-8 years older (Table 1). Among all twins, these percentages were almost identical $(29 \%, 22 \%, 13 \%)$ (Supplementary Table 4). Around $50 \%$ of all twins had a partner who was at least two years older, and only $9 \%$ of female twins had a partner who was at least two years younger.

Table 1 shows for complete twin pairs the mean values and the standard errors computed for the variables age at marriage and age, and the distribution of the age gap conditional on the other variables included in the analysis (Supplementary Table 4 for all twins). In 2010, the mean age of the women in our population was 48.3 years, both for the complete pairs and all twins. On average, the women in woman-older couples were older and married at a later age.

When we looked at the other characteristics of the individuals within the complete twin pairs, we found that about $79 \%$ of the women were employed, about $20 \%$ were out of the labor force, and $1 \%$ were unemployed. We also found that $54.3 \%$ of unemployed women, $50.9 \%$ of women out of the labor force, and $49.4 \%$ of employed women were in a man-older marriage (an age gap of more than two years) (Table 1). The results further indicated that $6 \%$ of the women in the population were childless, $14 \%$ had one child, $53 \%$ had two children, and $27 \%$ had three or more children. About $58 \%$ of the childless women were in a man-older relationship (Table 1$)$. Around half (49\%) of the most educated women (ISCED 7) were in a similar-age marriage (an age gap of between -2 and +2 years), while the corresponding shares were lower in the other education groups: for example, $54.3 \%$ of the less educated women were in a man-older marriage (Table 1). When we examined the income of the spouse, we found that $61.8 \%$ of the women with a spouse with a low income were in a man-older relationship, while only $39.8 \%$ of the women married to a man with a high income had an age difference of more than two years.

The findings were similar when we looked at all of the individuals included in the twin registry. For example, we found that in $2010,76 \%$ of these individuals were employed, $23 \%$ were out of the labor force, and $1 \%$ were unemployed; and that $7 \%$ of the women in the population were childless, $15 \%$ had one child, $52 \%$ had two children, and $26 \%$ had three or more children.

\section{Within-Twin Comparison}

We performed a comparison within twin pairs, computing the absolute differences between the gross incomes of the two individuals in each pair. We then plotted the age gap of twin 1 against the age gap of twin 2, and added the difference in their gross incomes as a third variable (Fig. 1). The objective was to determine whether the income differences between each twin in a pair were correlated with the differences in their age gaps relative to their respective partners. If the differences in income could be explained by the marital age differences, we would expect to see more darkly shaded points in the 
upper-left and bottom-right corners of Fig. 1. Most of the data points were clustered in the top-right quadrant, reflecting the tendency of women to marry older men. However, there was no evidence that on average across the twin pairs, the twin with the older partner had either a lower or a higher personal income level than the twin with the younger partner-a result that is confirmed both visually and statistically.

To investigate whether genetic similarities between twins might have been influencing our results, we checked whether identical (monozygotic) twins differed from fraternal (dizygotic) twins with respect to the correlation between the age gaps and the differences in gross income. While we found that identical twins had a higher propensity to marry partners of the similar age (correlation $=0.14$ ) than fraternal twins (correlation $=0.03$ ), the results were otherwise similar and non-significant for both types of twins.

\section{Quantile Regression Model}

Next, we expanded our dataset to include all of the women, regardless of whether their twin was also alive and married, to examine whether the lack of association found between the age gaps and the incomes might be attributable to the small size of the complete twin pair sample. In adding these individuals, we lost the ability to control for early environment through the twin design, but substantially increased our population size, from 4,716 to 13,354. The results of the estimation are shown in Table 2 (older cohorts) and in Table 3 (younger cohorts).

We found a small but statistically significant association between the age gap and the medium-low and the medium-high earners in the older cohort. Ceteris paribus, an increase of one year in marital age difference corresponded to an increase of about 74 dollars for women earning a medium-low gross income, and an increase of about 124 dollars for women earning a high gross income. No statistically significant association was found within any of the income quantiles in the younger cohort.

We also controlled for the effects of age, age at marriage, employment status, highest education attained, number of children, retirement status, and the gross income of the partner. In the older cohort, increasing age was negatively associated with income among low to median earners, but this association was not significant among the top quartile of income earners. The effect was reversed for the younger cohort subpopulation; i.e., increasing age was associated with increased income. A oneyear increase in the age at marriage was positively associated with personal income. This effect was greater in absolute terms among women who earned more in the older cohort, but it was significant for the third and the fifth quantiles only in the younger cohort.

Being employed (rather than being unemployed) strongly increased net income in all quantiles, and this effect was strongest $\left(15,732\right.$ dollars) among those earning a median-high ( $4^{\text {th }}$ quantile) income in the older cohort and among those earning a very high income $(14,273$ dollars) in the younger cohort. Being

\footnotetext{
${ }^{6} \mathrm{~A}$ t-test further confirmed this result ( $p$-value $=0.80$ ).
} 
out of the labor force was most detrimental for women earning below the median income in both cohorts.

Among the women who were out of the labor force, some were receiving retirement income (early retirement or retirement). In the younger cohort only, the early retirement category was observed, based on the ages of the women. Among the older cohort, being in early retirement reduced the income of the women in the third to fifth quantiles, while it strongly increased the income of the women in the first and second quantiles. Being retired increased the gross income of the women in the first two quantiles. Among the younger cohort, being in early retirement reduced the income of the women in all quantiles except the lowest one, for whom the effect was positive.

As expected, increasing levels of education were related to higher income, and these associations were stronger at the higher ends of the income distribution, and in the younger cohort. The number of children was generally not associated with income in the older cohorts, whereas in the younger cohorts it had a negative impact on income among medium to high earners, especially at higher parities. Moreover, a positive impact was observed among the lower income classes at lower parities.

Finally, there was a high degree of earnings homogamy among partners: i.e., the higher the gross personal income of the male spouse, the greater the income of the female partner. This relationship was observed in both cohorts, albeit with different magnitudes.

\section{Discussion}

Our analyses showed that the age gap between partners had little to no effect on female earnings. This result was found both within twin pairs, whereby the twin with the older partner was compared to the twin with the younger partner; and in an extended sample that included all female twins, regardless of whether the other twin was living or married. We hypothesized that the larger the age gap between the woman and her male partner was, the greater the income penalty for the woman would be. Our hypothesis was premised on the idea that an older male partner would have a higher income than a same-aged male partner. Instead, we found that having a larger age gap had a small positive impact on the incomes of middle wage earners of the older cohort only, and no effect among lower or high income earners. In the present data, the highest income of older partners was observed for couples with an age gap of between two and five years.

The finding that wages were generally unaffected by partnering with an older man could be attributed to heterogeneous groups of women entering men-older partnerships. Labor income generally increases with age until around age 50 (Lee and Ogawa 2011). In some cases, an older (wealthier) man might be more attractive to a career-oriented woman seeking further income gains. In other cases, a woman may, as hypothesized, have made compromises in her own career trajectory while prioritizing that of her older partner in order to maximize family wealth. 
While the above mechanisms have not been directly tested, some indirect evidence supporting the first of these potential mechanisms exists in the educational homogamy literature. Dribe and Nysted (2013) found that Swedish individuals in educational hypergamous unions (i.e., those with a better educated partner) out-earned those in educational homogamous unions, irrespective of gender. Most of these effects were, however, explained by the selection of high-productivity individuals into hypergamous unions, rather than by an actual impact on earnings from partner selection. Similar dynamics could be driving our results if strongly career-oriented women were self-selecting into men-older partnerships.

Selection effects can also operate through the relative success or failure in the marriage market, with men who marry substantially younger women being more negatively selected through other individual characteristics than men who partner with similarly-aged women. A study conducted in the U.S. found that the older a man was when he married, the more extreme the age difference to his partner was likely to be (England and McClintock 2009). Based on U.S. data, Mansour and McKinnish (2013) showed that men and women in age-dissimilar marriages were negatively selected in terms of education and income levels, cognitive abilities, and physical attractiveness. Although women married to younger men had higher incomes than women in age-similar marriages, this was due to longer hours spent at work rather than higher wages (Mansour and McKinnish 2013). An analysis of Swedish data suggested that individuals with high levels of education and income were more likely to be in an age-similar marriage, whereas individuals with low levels of education and income were more likely to be in an age-dissimilar marriage (Gustafson and Fransson 2015). In high-income countries such as Sweden, the increasing enrolment of young men and women in higher education institutions may be associated with more exposure to and time spent with people of a similar age, and may thus promote age-similar partnerships (Gustafson and Fransson 2015).

Alternatively, large age gaps could signal a second marriage, as a divorced or widowed man is more likely to enter a man-older union than a man entering a first marriage (Drefahl 2010a; Shafer 2013). There is some evidence that men who divorce have steeper and longer-term declines in household income than women who divorce (Drefahl 2010b). Thus, it is possible that a woman entering into a marriage with a divorced man has fewer incentives to make compromises in her own career trajectory in order to maximize the household income.

Women in man-older unions have also been shown to retire earlier than women in age-similar unions (Arber and Ginn 1995; Blau 1998; Johnson 2004). Moreover, women who had a younger spouse were more likely than men to retire before age 65 , whereas men who had a younger spouse were more likely than women to stay active in the labor force (Gustafson 2015). Thus, women could still run the risk of having a low income in retirement as a result of having made lower lifetime contributions. However, this is likely to be the case for only a small proportion of women. In Sweden, the percentage of couples who synchronized retirement (the same or plus/minus one year) was about $49 \%$ among couples with no age difference, was 9-10\% among couples with a five-year age gap, and was even smaller among couples with a larger age gap, irrespective of the sex of the older partner (Gustafson 2015). However, other studies have found that the marital age gap was unrelated to early retirement, and that synchronization patterns were similar in men and women (Dahl, Nilsen et al. 2003; Syse, Solem et al. 2014). 
Our use of female gross income as a marker of career success may be regarded as a potential limitation of the study. Income might not capture all dimensions, and other variables, such as the number of promotions, might have been a better proxy for career success. However, this information was not available in our data. Moreover, we were unable to discern whether higher income comes from higher wages or more hours worked. The official statistics suggest that the gender wage gap among part-time employees is much smaller than among full-time workers (Danmarks Statistik 2012). It has also been shown that in recent years, the share of Danish women in full-time employment has increased substantially, whereas the share of Danish men in part-time employment has increased only slightly (OECD 2016).

We looked for an association between a woman's current earnings and the age gap in her current marriage in 2010. If a woman was divorced and remarried, an earlier marriage at a critical life stagesuch as surrounding the birth of her first child-may have had a more important influence on her career trajectory. To test this possibility, we excluded all women who had divorced and remarried from the analysis. The results from this smaller sample were qualitatively similar, and none of our conclusions changed.

Another limitation is that divorced couples were excluded from the analysis. If the likelihood of divorce was also related to both the size of the age gap and lower- or higher-than-expected earnings, this exclusion could have biased our results. To ensure that these issues were not influencing our results, we ran a model that included divorced couples in the analysis. The magnitude and the direction of the coefficients in this model were similar to those performed on married couples only, although the coefficients for the age gap were statistically significant for all quantiles except the highest in the older cohorts, while they were still not significant in the younger cohorts.

There might be some question as to whether twins are representative of the Danish female population. Research evidence has shown that twins marry at slightly older ages and have lower marriage rates than singletons, and that female but not male twins have lower divorce rates than singletons (Kaprio, Koskenvuo et al. 1979; Petersen, Martinussen et al. 2011). These findings suggest that while the experience of having been in a twin relationship may reduce an individual's need for marriage; once married, this same experience could be associated with a greater ability to maintain a long-term relationship. However, other studies have found no evidence of twin-singleton differences with respect to marital histories (Pearlman 1990; Middeldorp, Cath et al. 2005) or fecundity (Christensen, Basso et al. 1998).

Although studies of older cohorts born in the 1950-1960s have consistently reported that twins have lower cognitive abilities and academic achievements than singletons from childhood to early adulthood (Record, McKeown et al. 1970; Myrianthopoulos, Nichols et al. 1976; Posthuma, De Geus et al. 2000; Deary, Pattie et al. 2005), studies of more recent cohorts of twins born in 1986-88 have shown that their school performance in adolescence is similar to that of singletons. This shift is most likely due to improved obstetric and pediatric practices, which have largely ameliorated the cognitive disadvantage in twins (Christensen, Petersen et al. 2006). However, while any cognitive differences might be expected to reduce the earning power of twins with respect to singletons, we would not expect these differences to 
change the relationship between a woman's earnings and the difference between her age and that of her husband. To evaluate the representativeness of the results from the unpaired twin analysis, we also analyzed a $5 \%$ random sample of the total population. The methodological strategies were the same as those used for the twin analysis, with the exception of childbearing, since this information was not available. The magnitude and the direction of the coefficients were in line with the original results for the old cohort, although we observed a statistically significant effect of the age gap on income in all of the quantiles, except in the lowest one. The impact of the age gap on income was slightly different among the younger cohorts of this random sample of the population than among the twin population. In the $5 \%$ sample, the age gap reduced the gross income of women in all quantiles ${ }^{7}$; while in the twin population, negative associations between the age gap and income were observed in the lowest two quantiles (although these associations were not statistically significant). A possible explanation for these differences in the results of the $5 \%$ sample and the twin population is that we could not control for childbearing in the $5 \%$ population. Although the analysis of all twins yields similar results for the association between the age gap and income with and without controlling for the number of children, we are not able to assert that the same lack of association would be observed in the $5 \%$ sample. Thus, it is possible that the effect of childbearing for this population is captured by the age gap in our analysis of the $5 \%$ population ${ }^{8}$. Another possible explanation is that some other unobserved characteristics related to partner selection are different in twins and in singletons. This issue merits further research, as exploring it could shed additional light on the representativeness of twin populations and/or on factors affecting partnering in general.

A final question is how generalizable our results are to other countries with different welfare regimes and attitudes toward gender equality.

During the working years of these cohorts of women, the female labor force participation rates in Denmark have consistently been much higher than in other OECD countries (Jaumotte 2003; OECD 2016). These high participation rates may be partly attributable to Denmark's generous family policies, which provide for long paid parental leave and affordable, public child care (Thévenon 2013). Such policies have been linked to higher female participation rates (Thévenon and Solaz 2013), but also to higher rates of part-time employment and employment in lower-level positions (Blau and Kahn 2013). Indeed, nearly one in five Danish women was engaged in part-time employment (less than 30 hours per week) in 2010; a share that was about 2.5 percentage points higher than the OECD average (OECD 2016). Compared with the OECD average, Danish women are also more heavily represented in the public sector (OECD 2015), which generally offers more opportunities for part-time employment (OECD 2016) and higher pay than the private sector (INDEX 2015; Jahan, Jespersen et al. 2015). It is possible that women in a man-older marriage are more likely to work part-time with a higher salary in order to have more family time, while women in a similarly-aged marriage may choose to work full-time with a lower salary. On the other hand, domestic work and child care are more evenly distributed between the sexes in Denmark (Craig and Mullan 2010), with large shares of fathers taking paternity leave (Danmarks Statistik 2012). Finally, contrary to findings for other settings, our results showed that neither marriage

\footnotetext{
${ }^{7}$ The estimates of the parameters were statistically significant in the lowest two and medium quantiles.

${ }^{8}$ The effect of childbearing for twins in the younger cohorts was strongly negative, especially at high parities.
} 
nor the number of children had negative effects on female wage levels in Denmark (Gupta and Smith 2002). Greater gender parity in household work should allow women greater flexibility in their career choices. Nevertheless, the net effect of these differences is that the gender pay gap in hourly gross earnings in Denmark is around the average for European countries (Eurostat 1994-2014).

Through taxes and transfers, net income is more equally distributed in the Danish welfare state model than it is in other high-income countries (OECD 2016). In countries with a steeper income distribution, partner choice might be more critical in maximizing family income. Whether entering a man-older union was associated with a reduction in women's wages would then depend on the degree to which careeroriented women are self-selecting into man-older relationships, and the degree to which women are making compromises in their own career to maximize the career potential of their husband. This pattern may differ depending on the country and time period.

Partnering with an older or a younger man does not appear to have a direct impact on women's earnings, at least in Denmark. Future research should explore employment type (part-time versus fulltime) and employment sector (public versus private), and extend this analysis to countries with different social welfare systems and less egalitarian gender norms. 
Table 1. Descriptive statistics of the complete pairs subpopulation $(n=4716)$. Complete pairs refers to individuals within a twin-pair in which both twins were alive and married in 2010. A negative number denotes a woman-older couple.

\begin{tabular}{|c|c|c|c|c|c|c|c|c|c|}
\hline Marital age gap & $\begin{array}{l}+8 \text { or } \\
\text { more }\end{array}$ & $\begin{array}{l}+5 \text { to } \\
+8\end{array}$ & $\begin{array}{l}+2 \text { to } \\
+5\end{array}$ & $\begin{array}{l}+1 \text { to } \\
+2\end{array}$ & -1 to +1 & -1 to -2 & -2 to -5 & -5 to -8 & $\begin{array}{l}-8 \text { or } \\
\text { less }\end{array}$ \\
\hline \%* & 8.1 & 12.2 & 29.6 & 13.2 & 23.2 & 5.3 & 5.9 & 1.6 & 0.9 \\
\hline Age at marriage & 30.8 & 28.8 & 28.0 & 28.0 & 28.9 & 31.3 & 34.1 & 40.3 & 42.6 \\
\hline (mean, (SD)) & (8.4) & (8.3) & (7.4) & $(6.8)$ & (6.4) & (7) & (7.3) & (8.1) & (5.4) \\
\hline Age & 47.8 & 48.4 & 49.0 & 48.5 & 47.5 & 47.0 & 47.9 & 51.5 & 52.3 \\
\hline (mean, (SD)) & (9.7) & $(10.1)$ & $(10.1)$ & $(10.0)$ & $(10.2)$ & (9.3) & (9.6) & (7.6) & (7.5) \\
\hline \multicolumn{10}{|l|}{ Employment } \\
\hline Employed & 7.8 & 12.0 & 29.6 & 12.7 & 23.7 & 5.9 & 5.8 & 1.6 & 0.9 \\
\hline $\begin{array}{l}\text { Out of labor } \\
\text { force }\end{array}$ & 9.3 & 13.0 & 28.6 & 15.2 & 21.4 & 3.3 & 6.3 & 1.7 & 1.2 \\
\hline Unemployed & 6.8 & 8.5 & 39.0 & 13.6 & 22.0 & 5.1 & 0.0 & 3.4 & 1.7 \\
\hline \multicolumn{10}{|l|}{ Education } \\
\hline ISCED $1 / 2$ & 9.9 & 14.2 & 30.2 & 13.4 & 18.1 & 4.3 & 6.4 & 2.0 & 1.5 \\
\hline ISCED 3 & 7.5 & 11.9 & 26.9 & 15.7 & 21.6 & 6.7 & 7.5 & 1.5 & 0.7 \\
\hline ISCED 5/6 & 7.7 & 11.4 & 30.1 & 13.0 & 24.4 & 5.5 & 5.5 & 1.6 & 5.9 \\
\hline ISCED 7 & 6.6 & 15.6 & 19.8 & 15.1 & 27.8 & 6.1 & 8.0 & 0.5 & 0.5 \\
\hline \multicolumn{10}{|l|}{ Retirement } \\
\hline Not retired & 8.0 & 12.2 & 29.6 & 12.8 & 23.3 & 5.7 & 5.9 & 1.6 & 0.9 \\
\hline Early retired & 13.6 & 12.8 & 27.7 & 12.8 & 18.2 & 2.5 & 7.0 & 2.5 & 2.9 \\
\hline Early beneficiary & 4.6 & 11.7 & 31.6 & 18.9 & 23.8 & 3.9 & 4.2 & 0.7 & 0.7 \\
\hline Retired & 11.5 & 10.3 & 26.4 & 13.8 & 28.7 & 2.3 & 4.6 & 2.3 & 0.0 \\
\hline \multicolumn{10}{|l|}{ Children } \\
\hline 0 & 19.0 & 13.8 & 24.6 & 11.8 & 15.9 & 3.5 & 8.0 & 2.1 & 1.4 \\
\hline 1 & 10.3 & 13.1 & 27.8 & 11.7 & 19.8 & 5.0 & 7.3 & 3.3 & 1.9 \\
\hline 2 & 7.0 & 12.3 & 30.3 & 13.3 & 24.7 & 5.2 & 5.1 & 1.3 & 0.8 \\
\hline
\end{tabular}




\begin{tabular}{|c|c|c|c|c|c|c|c|c|c|}
\hline $3+$ & 6.7 & 11.1 & 30.0 & 14.1 & 23.6 & 6.3 & 6.2 & 1.4 & 0.6 \\
\hline \multicolumn{10}{|l|}{ Gross income } \\
\hline \multicolumn{10}{|l|}{ spouse } \\
\hline Low & 12.6 & 17.3 & 31.9 & 11.6 & 16.5 & 3.2 & 4.6 & 1.3 & 0.9 \\
\hline Medium-low & 9.3 & 10.8 & 30.1 & 12.6 & 22.4 & 5.1 & 6.8 & 1.7 & 1.2 \\
\hline Medium-high & 4.8 & 12.3 & 29.1 & 14.4 & 24.8 & 7.1 & 5.4 & 1.4 & 0.8 \\
\hline High & 6.3 & 9.1 & 27.4 & 14.0 & 28.1 & 5.8 & 6.4 & 2.1 & 0.9 \\
\hline
\end{tabular}

* All percentages in row 
Fig. 1 Age gap of twin 1 versus age gap of twin 2. Darker points indicate bigger absolute differences in gross income between twin 1 and twin 2



Absolute Differences Gross Income Categories $\quad<5000 \quad<11300 \quad<21900 \quad<21900$ 
Table 2. Quantile regression for the association of age gap with gross income in the older cohort (19451964).

\begin{tabular}{|c|c|c|c|c|c|}
\hline Quantiles & 0.10 & 0.25 & 0.50 & 0.75 & 0.90 \\
\hline Intercept & $32611^{* * *}$ & $33973 * * *$ & $32699 * * *$ & $29354^{* * *}$ & $40950 * * *$ \\
\hline Age gap & 79 & $74^{*}$ & 69 & $124^{*}$ & 107 \\
\hline Age & $-257 * * *$ & $-213 * * *$ & $-153^{* * *}$ & -18 & -77 \\
\hline Age marriage & $85^{* * *}$ & $81 * * *$ & $110^{* * *}$ & $162^{* * *}$ & $218^{* * *}$ \\
\hline \multicolumn{6}{|c|}{ Retirement status (ref.: not retired) } \\
\hline Early retired & $12313^{* * *}$ & $13163^{* * *}$ & $-2210 * *$ & $-2290 *$ & $-4228 \dagger$ \\
\hline $\begin{array}{l}\text { Early retirement } \\
\text { beneficiary }\end{array}$ & $22180 * * *$ & $22726 * * *$ & $5763 * * *$ & $2454^{* *}$ & -292 \\
\hline Retired & $17011^{* * *}$ & $17966^{* * *}$ & 1028 & -1146 & -3965 \\
\hline \multicolumn{6}{|c|}{ Employment status (ref.: unemployed) } \\
\hline Employed & $7608 * * *$ & $10441^{* * *}$ & $14898 * * *$ & $15732^{* * *}$ & $14094^{* * *}$ \\
\hline Out of labor force & $-22438 * * *$ & $-23700 * * *$ & $-6352 * * *$ & $-6257 * * *$ & $-7558 \dagger$ \\
\hline \multicolumn{6}{|c|}{ Education (ref.: ISCED 1/2) } \\
\hline ISCED 3 & -1232 & 399 & $3516^{* *}$ & $4177^{*}$ & $8051 \dagger$ \\
\hline ISCED 5/6 & $2578 * * *$ & $3871 * * *$ & $5363^{* * *}$ & $7471 * * *$ & $9896 * * *$ \\
\hline ISCED 7 & $17230 * * *$ & $22061^{* * *}$ & $28219 * * *$ & $42414^{* * *}$ & $65866^{* * *}$ \\
\hline \multicolumn{6}{|c|}{ No. of children (ref.: $\mathbf{0}$ children) } \\
\hline 1 child & 658 & 559 & 454 & 353 & 980 \\
\hline 2 children & 1544 & 895 & 14 & -788 & -1668 \\
\hline $3+$ children & 924 & 612 & -220 & -904 & -2842 \\
\hline \multicolumn{6}{|c|}{ Spouse's income (ref.: low) } \\
\hline Medium-low & 0 & $820 *$ & 729 & $1765^{* *}$ & $2191 *$ \\
\hline Medium-high & 255 & $1281^{* *}$ & $1963^{* * *}$ & $3528 * * *$ & $5077^{* * *}$ \\
\hline High & -964 & $951^{*}$ & $3946 * * *$ & $7383 * * *$ & $11800 * * *$ \\
\hline
\end{tabular}


†p $<.10 ;{ }^{*} p<.05 ;{ }^{* *} p<.01 ; *^{* *} p<.001$ 
Table 3. Quantile regression for the association of age gap with gross income in the younger cohort (1965-1990)

\begin{tabular}{|c|c|c|c|c|c|}
\hline Quantiles & 0.10 & 0.25 & 0.50 & 0.75 & 0.90 \\
\hline Intercept & 4573 & $7274^{* *}$ & $9584^{* * *}$ & $8703^{* * *}$ & 2683 \\
\hline Age gap & -5 & -3 & 19 & 99 & 9 \\
\hline Age & $267^{* * *}$ & $296^{* * *}$ & $396 * * *$ & $602 * * *$ & $899 * * *$ \\
\hline Age marriage & -22 & 50 & $111^{*}$ & $133^{*}$ & $256^{*}$ \\
\hline \multicolumn{6}{|c|}{ Retirement status (ref.: not retired) } \\
\hline Early retired & $6352 * * *$ & $-3094^{*}$ & $-6469 * * *$ & $-7442 * * *$ & $-12967 * * *$ \\
\hline \multicolumn{6}{|c|}{ Employment status (ref.: unemployed) } \\
\hline Employed & $7575^{* * *}$ & $11054^{* * *}$ & $11859 * * *$ & $11864^{* * *}$ & $14273^{* * *}$ \\
\hline Out of labor force & $-16143^{* * *}$ & $-6276 * * *$ & $-3879 * *$ & $-4164 * *$ & -246 \\
\hline \multicolumn{6}{|c|}{ Education (ref.: ISCED 1/2) } \\
\hline ISCED 3 & $2630 \dagger$ & $2114^{*}$ & $4054 * *$ & $7250 * * *$ & $5305^{* *}$ \\
\hline ISCED 5/6 & $5828 * * *$ & $5923 * * *$ & $5960 * * *$ & $7844^{* * *}$ & $7817^{* * *}$ \\
\hline ISCED 7 & $14415^{* * *}$ & $20849 * * *$ & $24789 * * *$ & $31608 * * *$ & $36849 * * *$ \\
\hline \multicolumn{6}{|c|}{ No. of children (ref.: 0 children) } \\
\hline 1 child & $4120^{* *}$ & $1639 \dagger$ & -338 & -1208 & -1325 \\
\hline 2 children & $4357^{* *}$ & $1906 *$ & -419 & -975 & -1445 \\
\hline $3+$ children & $2403 \dagger$ & -386 & $-2846 * *$ & $-3936 * * *$ & $-6378 * * *$ \\
\hline \multicolumn{6}{|c|}{ Spouse's income (ref.: low) } \\
\hline Medium-low & $3276 * * *$ & $1547^{*}$ & 925 & -878 & $-2268 \dagger$ \\
\hline Medium-high & $3613 * * *$ & $2619 * * *$ & $2864 * * *$ & $2833^{* * *}$ & $2541 \dagger$ \\
\hline High & 1608 & $2439 * * *$ & $4509 * * *$ & $6968 * * *$ & $11767^{* * *}$ \\
\hline
\end{tabular}




\section{References}

Arber, S. and J. Ginn (1995). Choice and Constraint in the Retirement of Older Married Women. Connecting Gender and Ageing: A Sociological Approach. S. Arber and J. Ginn. Buckingham, UK,, Open University Press: 69-86.

Arulampalam, W., A. L. Booth, et al. (2007). "Is There a Glass Ceiling over Europe? Exploring the Gender Pay Gap across the Wage Distribution." Industrial \& Labor Relations Review 60(2): 163-186.

Atkinson, M. P. and B. L. Glass (1985). "Marital Age Heterogamy and Homogamy, 1900 to 1980." Journal of Marriage and Family 47(3): 685-691.

Baadsgaard, M. and J. Quitzau (2011). "Danish registers on personal income and transfer payments." Scandinavian Journal of Public Health 39(7 suppl): 103-105.

Banks, C. A. and P. Arnold (2001). "Opinions Towards Sexual Partners with a Large Age Difference." Marriage \& Family Review 33(4): 5-18.

Becker, G. (1981). A Treatise on the Family, National Bureau of Economic Research, Inc.

Berardo, F. M., J. Appel, et al. (1993). "Age dissimilar marriages: Review and assessment." Journal of Aging Studies 7(1): 93-106.

Bergstrom, T. C. and M. Bagnoli (1993). "Courtship as a waiting game." Journal of political economy: 185-202.

Billari, F. (2005). "Partnership, childbearing and parenting: Trends of the 1990s." The new demographic regime. Population challenges and policy responses 5: 63-94.

Blau, D. M. (1998). "Labor Force Dynamics of Older Married Couples." Journal of Labor Economics 16(3): 595-629.

Blau, F. D. and L. M. Kahn (2000). "Gender Differences in Pay." Journal of Economic Perspectives 14(4): 75-99.

Blau, F. D. and L. M. Kahn (2013). "Female Labor Supply: Why Is the United States Falling Behind?" The American Economic Review 103(3): 251-256.

Blood, R. J. and D. Wolfe (1960). Husbands and wives: the dynamics of married living. New York, Free Press

Budig, M. J. and M. J. Hodges (2010). "Differences in Disadvantage: Variation in the Motherhood Penalty across White Women's Earnings Distribution." American Sociological Review 75(5): 705-728.

Buss, D. M. (1989). "Sex differences in human mate preferences: Evolutionary hypotheses tested in 37 cultures." Behavioral and Brain Sciences 12(01): 1-14.

Casterline, J. B., L. Williams, et al. (1986). "The Age Difference Between Spouses: Variations among Developing Countries." Population Studies 40(3): 353-374.

Christensen, K., O. Basso, et al. (1998). "Fecundability of female twins." Epidemiology 9(2): 189-192.

Christensen, K., I. Petersen, et al. (2006). "Comparison of academic performance of twins and singletons in adolescence: follow-up study." BMJ 333(7578): 1095-.

Christofides, L. N., A. Polycarpou, et al. (2013). "Gender wage gaps, 'sticky floors' and 'glass ceilings' in Europe." Labour Economics 21: 86-102.

Craig, L. and K. Mullan (2010). "Parenthood, Gender and Work-Family Time in the United States, Australia, Italy, France, and Denmark." Journal of Marriage and Family 72(5): 1344-1361.

Dahl, S. Å., Ø. A. Nilsen, et al. (2003). "Gender Differences in Early Retirement Behaviour." European Sociological Review 19(2): 179-198.

Danmarks Statistik (2012). Statistiske efterretninger: Dagpenge ved graviditet, fødsel og adoption 2011. . København: Danmarks Statistik.

Deary, I. J., A. Pattie, et al. (2005). "The Cognitive Cost of Being a Twin: Two Whole-Population Surveys." Twin Research and Human Genetics 8(04): 376-383.

Diez Minguela, A. M. (2010). Essays on marriage and female labour. PhD, University of Warwick. 
Drefahl, S. (2010a). "How does the age gap between partners affect their survival?" Demography 47(2): 313-326.

Drefahl, S. (2010b). Death in the family. PhD, Universität Rostock

Dribe, M. and P. Nystedt (2013). "Educational homogamy and gender-specific earnings: Sweden, 19902009." Demography 50(4): 1197-1216.

Esteve, A., C. Cortina, et al. (2009). "Long term trends in marital age homogamy patterns: Spain, 19222006." Population, English edition 64(1): 173-202.

Eurostat. (1994-2014). "The unadjusted Gender Pay Gap (GPG): 1994-2014. http://ec.europa.eu/eurostat/web/labour-market/earnings/database. Data accessed on 21/02/2017

", 2017.

Eurostat (2008). "The Life of Women and Men in Europe: A Statistical Portrait." Luxembourg: European Commission: 92-106.

Eurydice. (2014). "The Structure of the European Education Systems 2014/15: Schematic Diagrams ", 2016.

Eurydice. (2016). "The Danish education system.", 2016.

Evertsson, M. and A.-Z. Duvander (2010). "Parental Leave-Possibility or Trap? Does Family Leave Length Effect Swedish Women's Labour Market Opportunities?" European Sociological Review.

Fortin, N. M. (2008). "The Gender Wage Gap among Young Adults in the United States: The Importance of Money versus People." Journal of Human Resources 43(4): 884-918.

Fransen, E., J. Plantenga, et al. (2012). "Why do women still earn less than men? Decomposing the Dutch gender pay gap, 1996-2006." Applied Economics 44(33): 4343-4354.

Gough, M. and M. Noonan (2013). "A Review of the Motherhood Wage Penalty in the United States." Sociology Compass 7(4): 328-342.

Grunow, D. a. S. L.-S. (2004). Women's employment in Denmark: Are Danish women's careers marked by globalization? GLOBALIFE working paper series (52). Otto-Friederich-University Bamberg.

Gupta, N. D. and N. Smith (2002). "Children and Career Interruptions: The Family Gap in Denmark." Economica 69(276): 609-629.

Gustafson, P. (2015). "Spousal age differences and synchronised retirement." Ageing \& Society FirstView: 1-27.

Gustafson, P. and U. Fransson (2015). "Age Differences Between Spouses: Sociodemographic Variation and Selection." Marriage \& Family Review 51(7): 610-632.

Hancock, R., R. Stuchbury, et al. (2003). "Changes in the distribution of marital age differences in England and Wales, 1963 to 1998." POPULATION TRENDS-LONDON-: 19-25.

INDEX, G. E. (2015). Gender Equality Index 2015 - Measuring gender equality in the European Union 2005-2012. Publications Office of the European Union. E. I. f. G. Equality.

Jahan, S., E. Jespersen, et al. (2015). "Human development report 2015: Work for human development." UNDP: New York, NY, USA.

Jaumotte, F. (2003). "Female labour force participation: past trends and main determinants in OECD countries." OECD Working Paper No. 376.

Johansson, E.-A. (2010). "The effect of own and spousal parental leave on earnings." Working paper IFAU 2010-4. Institute for Labour Market Policy Evaluation

Johnson, R. W. (2004) "Do Spouses Coordinate Their Retirement Decisions? ." An Issue in Brief.

Kahn, J. R., J. García-Manglano, et al. (2014). "The Motherhood Penalty at Midlife: Long-Term Effects of Children on Women's Careers." Journal of Marriage and Family 76(1): 56-72. 
Kaprio, J., M. Koskenvuo, et al. (1979). "The Finnish twin registry: baseline characteristics. Section I: materials methods, representativeness and results for variables special to twin studies." Kansanterveystieteen julkaisuja M 47: 1979.

Klein, T. (1996). "Der Altersunterschied zwischen Ehepartnern: Ein neues Analysemodell [Agedifferences between marital partners. A new analytic model]." Zeitschrift fuer Soziologie 25(5): 346-370.

Koenker, R., S. Portnoy, et al. (2016). Package 'quantreg'. http://www.r-project.org.

Kohler, H.-P., J. R. Behrman, et al. (2011). "Social Science Methods for Twins Data: Integrating Causality, Endowments, and Heritability." Biodemography and Social Biology 57(1): 88-141.

Kroenker, R. (2005). Quantile Regression. New York.

Kunze, A. (2005). "The evolution of the gender wage gap." Labour Economics 12(1): 73-97.

Larsen, J. (2015). The women's movement in Denmark. Kvinfo.

Lee, S.-H. and N. Ogawa (2011). Labor Income over the Life-Cycle. Population Aging and the Generational Economy: A Global Perspective. R. Lee and A. Mason. Cheltenham, Edward Elgar Publishing Limited: 109-135.

Lehmiller, J. J. and C. R. Agnew (2006). "Marginalized relationships: The impact of social disapproval on romantic relationship commitment." Personality and Social Psychology Bulletin 32(1): 40-51.

Lehmiller, J. J. and C. R. Agnew (2008). "COMMITMENT IN AGE-GAP HETEROSEXUAL ROMANTIC RELATIONSHIPS: A TEST OF EVOLUTIONARY AND SOCIO-CULTURAL PREDICTIONS." Psychology of Women Quarterly 32(1): 74-82.

Mandel, H. and M. Semyonov (2005). "Family Policies, Wage Structures, and Gender Gaps: Sources of Earnings Inequality in 20 Countries." American Sociological Review 70(6): 949-967.

Mandel, H. and M. Semyonov (2006). "A Welfare State Paradox: State Interventions and Women's Employment Opportunities in 22 Countries." American journal of sociology 111(6): 1910-1949.

Mansour, H. and T. McKinnish (2013). "Who Marries Differently Aged Spouses? Ability, Education, Occupation, Earnings, and Appearance." Review of Economics and Statistics 96(3): 577-580.

Middeldorp, C. M., D. C. Cath, et al. (2005). "Twin and Genetic Effects on Life Events." Twin Research and Human Genetics 8(03): 224-231.

Miller, P. W. (2009). "The Gender Pay Gap in the US: Does Sector Make a Difference?" Journal of Labor Research 30(1): 52-74.

Mu, Z. and Y. Xie (2014). "Marital age homogamy in China: A reversal of trend in the reform era?" Social Science Research 44: 141-157.

Myrianthopoulos, N. C., P. L. Nichols, et al. (1976). "Intellectual Development of Twins - Comparison with Singletons." Acta geneticae medicae et gemellologiae: twin research 25(01): 376-380.

Niedomysl, T., J. Östh, et al. (2010). "The Globalisation of Marriage Fields: The Swedish Case." Journal of Ethnic and Migration Studies 36(7): 1119-1138.

OECD (2015). Women in public sector employment. Government at a Glance 2015. Paris, OECD Publishing.

OECD (2016). "OECD Labour Force Statistics 2015." OECD Publishing.

OECD (2016). Part-time employment rate (indicator).

OECD (2016). Society at a Glance 2016: OECD Social Indicators (http://dx.doi.org/10.1787/9789264261488-en). Paris, OECD Publishing.

Pearlman, E. M. (1990). "Separation-Individuation, Self-Concept, and Object Relations in Fraternal Twins, Identical Twins, and Singletons." The Journal of Psychology 124(6): 619-628.

Pedersen, C. B. (2011). "The Danish Civil Registration System." Scandinavian Journal of Public Health 39(7 suppl): 22-25. 
Petersen, I., T. Martinussen, et al. (2011). "Lower Marriage and Divorce Rates Among Twins Than Among Singletons in Danish Birth Cohorts 1940-1964." Twin Research and Human Genetics 14(02): 150157.

Petersson, F., M. Baadsgaard, et al. (2011). "Danish registers on personal labour market affiliation." Scandinavian Journal of Public Health 39(7 suppl): 95-98.

Poppel, F. V., A. C. Liefbroer, et al. (2001). "Love, necessity and opportunity: Changing patterns of marital age homogamy in the Netherlands, 1850-1993." Population Studies 55(1): 1-13.

Posthuma, D., E. J. De Geus, et al. (2000). "Twin-singleton differences in intelligence?" Twin Research and Human Genetics 3(02): 83-87.

Presser, H. B. (1975). "Age differences between spouses: Trends, patterns, and social implications." American Behavioral Scientist 19(2): 190-205.

$R$ Core Team (2014). R: A language and environment for statistical computing. R Foundation for Statistical Computing, Vienna, Austria. 2013, ISBN 3-900051-07-0.

Record, R. G., T. McKeown, et al. (1970). "An investigation of the difference in measured intelligence between twins and single births*." Annals of Human Genetics 34(1): 11-20.

Rosholm, M. and N. Smith (1996). "The Danish gender wage gap in the 1980s: A panel data study " Oxford Economic Papers 48(2): 254-279.

Säve-Söderbergh, J. (2007). "Are women asking for low wages? gender differences in wage bargaining strategies and ensuing bargaining success."

Seibert, S. E. a. M. L. K. (2001). "The Five-Factor Model of Personality and Career Success." Journal of Vocational Behaviour: 1-21.

Shafer, K. (2013). "Disentangling the relationship between age and marital history in age-assortative mating." Marriage \& Family Review 49(1): 83-114.

Skytthe, A., L. Christiansen, et al. (2012). "The Danish Twin Registry: Linking Surveys, National Registers, and Biological Information." Twin Research and Human Genetics FirstView: 1-8.

Skytthe, A., K. Ohm Kyvik, et al. (2011). "The Danish Twin Registry." Scandinavian Journal of Public Health 39(7 suppl): 75-78.

Statistics Denmark (2016). Average age of males and females getting married: http://www.statbank.dk/10001 Sejroegade 11 - DK-2100 Copenhagen.

Syse, A., P. E. Solem, et al. (2014). "Do Spouses Coordinate Their Work Exits? A Combined Survey and Register Analysis From Norway." Research on Aging 36(5): 625-650.

Tervola, J., A.-Z. Duvander, et al. (2016). Promoting parental leave for immigrant fathers - what role does policy play? . Stockholm Research Reports in Demography 2016: 14. Stockholm Stockholm University, Department of Sociology, Demography Unit

Thévenon, O. (2013). "Drivers of Female Labour Force Participation in the OECD." OECD Social, Employment and Migration Working Papers, No. 145.

Thévenon, O. and A. Solaz (2013). "Labour Market Effects of Parental Leave Policies in OECD Countries." OECD Social, Employment and Migration Working Papers, No. 141.

Vera, H., D. H. Berardo, et al. (1985). "Age Heterogamy in Marriage." Journal of Marriage and Family 47(3): 553-566.

Wahlberg, R. (2010). "The gender wage gap across the wage distribution in the private and public sectors in Sweden." Applied Economics Letters 17(15): 1465-1468.

West, C. and D. H. Zimmerman (1987). "Doing Gender." Gender and Society 1(2): 125-151. 
Supplementary Table 4. Descriptive statistics of all twins population $(n=13354)$. A negative number denotes a woman-older couple.

\begin{tabular}{|c|c|c|c|c|c|c|c|c|c|}
\hline Marital age gap & $\begin{array}{l}+8 \text { or } \\
\text { more }\end{array}$ & $\begin{array}{l}+5 \text { to } \\
+8\end{array}$ & $\begin{array}{l}+2 \text { to } \\
+5\end{array}$ & $\begin{array}{l}+1 \text { to } \\
+2\end{array}$ & -1 to +1 & -1 to -2 & -2 to -5 & -5 to -8 & $\begin{array}{l}-8 \text { or } \\
\text { less }\end{array}$ \\
\hline \%* & 9.1 & 12.7 & 28.7 & 13 & 22.3 & 5.3 & 6.3 & 1.8 & 0.8 \\
\hline $\begin{array}{l}\text { Age at marriage } \\
\text { (mean, }(\mathrm{SD}))\end{array}$ & $\begin{array}{l}30.9 \\
(8.5)\end{array}$ & $\begin{array}{l}29.3 \\
(8.3)\end{array}$ & $\begin{array}{l}28 \\
(7.4)\end{array}$ & $\begin{array}{l}28.5 \\
(7.3)\end{array}$ & $\begin{array}{l}29.2 \\
(6.9)\end{array}$ & $\begin{array}{l}31.8 \\
(7.1)\end{array}$ & $\begin{array}{l}34.9 \\
(7.4)\end{array}$ & $\begin{array}{l}39.6 \\
(7.8)\end{array}$ & $\begin{array}{l}43 \\
(5.5)\end{array}$ \\
\hline $\begin{array}{l}\text { Age } \\
\text { (mean, (SD)) }\end{array}$ & $\begin{array}{l}47.2 \\
(10.3)\end{array}$ & $\begin{array}{l}47.9 \\
(10.8)\end{array}$ & $\begin{array}{l}48.9 \\
(10.6)\end{array}$ & $\begin{array}{l}48.7 \\
(10.6)\end{array}$ & $\begin{array}{l}47.6 \\
(10.7)\end{array}$ & $\begin{array}{l}47.7 \\
(9.7)\end{array}$ & $\begin{array}{l}48.5 \\
(9.3)\end{array}$ & $\begin{array}{l}51 \\
(8.3)\end{array}$ & $\begin{array}{l}52.2 \\
(7.9)\end{array}$ \\
\hline \multicolumn{10}{|l|}{ Employment } \\
\hline Employed & 9.0 & 12.4 & 28.5 & 12.9 & 22.9 & 5.6 & 6.5 & 1.7 & 0.7 \\
\hline $\begin{array}{l}\text { Out of labor } \\
\text { force }\end{array}$ & 9.6 & 13.9 & 29.7 & 13.4 & 20.6 & 4.3 & 5.8 & 2.0 & 0.8 \\
\hline Unemployed & 11.6 & 9.5 & 27.6 & 13.1 & 25.1 & 4.0 & 4.0 & 4.0 & 1.0 \\
\hline \multicolumn{10}{|l|}{ Education } \\
\hline ISCED $1 / 2$ & 11.2 & 14.3 & 30.1 & 12.7 & 18.1 & 4.1 & 6.1 & 2.3 & 1.0 \\
\hline ISCED 3 & 10.8 & 14.9 & 25.7 & 16.5 & 18.9 & 4.9 & 5.9 & 1.4 & 1.1 \\
\hline ISCED 5/6 & 8.5 & 12.0 & 28.7 & 13.0 & 23.6 & 5.6 & 6.3 & 1.6 & 0.7 \\
\hline ISCED 7 & 9.2 & 13.6 & 23.4 & 13.4 & 24.7 & 6.8 & 7.5 & 1.3 & 0.2 \\
\hline \multicolumn{10}{|l|}{ Retirement } \\
\hline Not retired & 9.2 & 12.6 & 29.3 & 12.9 & 22.7 & 5.5 & 6.4 & 1.7 & 0.7 \\
\hline Early retired & 13.4 & 14.2 & 29.4 & 10.8 & 16.7 & 3.8 & 7.6 & 2.7 & 1.5 \\
\hline Early beneficiary & 5.7 & 12.6 & 33.5 & 15.9 & 22.2 & 3.8 & 4.4 & 1.4 & 0.5 \\
\hline Retired & 8.8 & 10.5 & 27.0 & 26.9 & 24.0 & 5.4 & 4.1 & 2.7 & 0.7 \\
\hline \multicolumn{10}{|l|}{ Children } \\
\hline 0 & 19.2 & 14.5 & 24.1 & 9.7 & 17.0 & 4.2 & 7.2 & 2.4 & 1.7 \\
\hline 1 & 12.3 & 12.4 & 26.7 & 11.5 & 21.3 & 4.6 & 7.2 & 2.9 & 1.1 \\
\hline 2 & 7.8 & 12.7 & 29.7 & 13.5 & 23.2 & 5.5 & 5.8 & 1.3 & 0.6 \\
\hline
\end{tabular}




\begin{tabular}{lccccccccc}
\hline $3+$ & 7.4 & 12.3 & 29.3 & 13.9 & 22.7 & 5.5 & 6.4 & 1.9 & 0.7 \\
$\begin{array}{l}\text { Gross income } \\
\text { spouse }\end{array}$ & & & & & & & & & \\
Low & 15.0 & 16.2 & 30.2 & 10.6 & 17.5 & 3.4 & 4.5 & 1.6 & 0.9 \\
Medium-low & 8.8 & 12.0 & 29.9 & 13.1 & 21.3 & 5.4 & 6.8 & 1.9 & 0.9 \\
Medium-high & 6.2 & 12.0 & 28.4 & 14.7 & 23.9 & 6.0 & 6.6 & 1.5 & 0.6 \\
High & 6.7 & 10.6 & 26.5 & 13.7 & 26.5 & 6.3 & 7.1 & 2.1 & 0.6 \\
\hline
\end{tabular}

